Radchenko Lidiia, Ivanenko Halyna, Krol Irina, Biletska Viktoriia, Yasko Liliia, Kozhanova Olga, Ermolova Valentina, Diomina Aliona. Interactive technologies during implementation of the olympic education into the student educational process. Pedagogy and Psychology of Sport. 2021;7(1):135-146. elSSN 2450-6605. DOI http://dx.doi.org/10.12775/PPS.2021.07.01.009

https://apcz.umk.pl/czasopisma/index.php/PPS/article/view/PPS.2021.07.01.009

https://zenodo.org/record/4624857

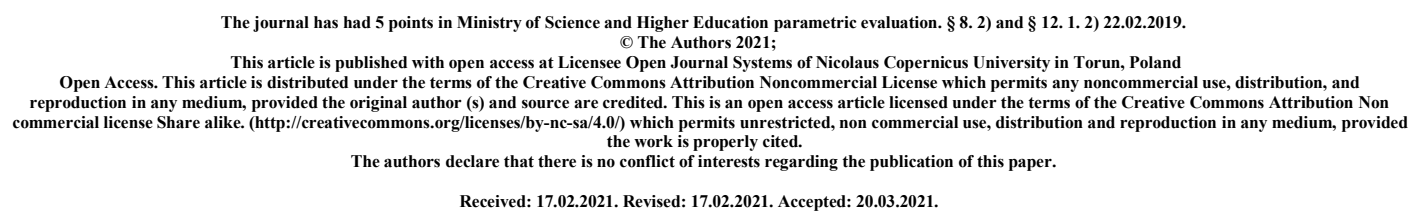

\title{
Interactive technologies during implementation of the olympic education into the student educational process
}

\author{
Radchenko Lidiia ${ }^{1 \mathrm{ABDE}}$, Ivanenko Halyna ${ }^{2 \mathrm{ABCD}}$, Krol Irina ${ }^{1 \mathrm{ADE}}$, Biletska Viktoriia ${ }^{2 \mathrm{CD}}$, \\ Yasko Liliia $^{2 \mathrm{CD}}$, Kozhanova Olga ${ }^{2 \mathrm{CD}}$, Ermolova Valentina ${ }^{1 \mathrm{ABE}}$, Diomina Aliona ${ }^{1 \mathrm{AB}}$
}

Authors' Contribution: A - Study design; B - Data collection; C - Statistical analysis; D Manuscript Preparation; E - Funds Collection

${ }^{1}$ National University for Physical Education and Sport of Ukraine

${ }^{2}$ Borys Grinchenko Kyiv University

*Corresponding authors:

Ivanenko Halyna

Borys Grinchenko Kyiv University

Kyiv, Ukraine

Email: h.ivanenko@kubg.edu.ua

Key words: interactive technologies, Olympic education, educational process, students.

\begin{abstract}
Introduction

Shift of priorities and social values in today's society leads to the need for constant improvement of educational process in higher education institutions.

The experts note (Bystrova Yu.V., 2015; Gladush V.A. \& Lysenko G.I., 2014; Naul R., Binder D., Ivanenko G., 2019) that the outdated practices prevail in today's practical activity of higher educational specialized institutions, the ideas of democratization are not sufficiently implemented. The main problems in the development of higher education institutions are student low motivation to acquire knowledge and drop in attendance. This situation necessitates rethinking of the principles, functions and technologies of managing specialist training in Physical Culture and Sports and, thereupon, develops new approaches to the organization of the pedagogical process in a higher education institution.
\end{abstract}


The analysis of special scientific and methodological literature indicates that today the ways of integration of the Olympic education into the school educational process have been extensively revealed (Armor K, Dagkas S., 2012), the educational potential of the Olympic movement has been elucidated (Bulatov M. \& Platonov V., 2018), the importance of integrating Olympic education into the specialist training in Physical Culture and Sports (Radchenko LO, 2016), the activity peculiarities of the Olympic Studies Centers operating as part of the specialized higher education institutions of Ukraine (Zagitova \& Radchenko, 2019) have been disclosed, whereas the problem of improving the educational process by integrating Olympic education into the educational process of higher education institutions remains a pressing scientific matter.

Today's educational requirements include the training of highly qualified specialists who are able to integrate the theoretical knowledge and practical skills acquired at a higher educational institution into an integral system effectively used in their professional activities. In order to successfully realize personal educational potential of future specialists in Physical Culture and Sports, the development conditions of the qualities such as criticism and nonstandard thinking, the ability to produce new ideas and work in a team, etc., must be created. Such tasks are facilitated by the use of interactive learning technologies in the educational process.

The working hypothesis is that the use of interactive learning technologies in the study of Olympic education related issues will improve the efficiency of student educational process in higher education institutions preparing future specialists in Physical Culture and Sports.

Aim of the Study: to provide the rationale for the use of interactive learning technologies while implementing the Olympic education into the student educational process.

\section{Material and methods.}

Research participants: 12 experts - members of the Olympic Academy of Ukraine, having more than 15 years of pedagogic experience at higher educational institutions, holding managerial positions at sphere-specific educational establishments.

69 students from 8 study groups of the $4^{\text {th }}$ year at the National University of Ukraine on Physical Education and Sport, who major in 0.17 'Physical Education and Sport'.

Organization of research.

The first step was to determine experts' opinion on the necessity to introduce Olympic education in the student training process.

The next step of the study was to determine the educational process efficiency according to I.S. Todorova (Todorova I.S\& Pavlenko V.I. 2011). This method employs that the respondents need to answer 20 questions that allow to determine the educational activity efficiency ratio, namely: total educational activity efficiency, motivational subsystem efficiency, operational subsystem efficiency, information subsystem efficiency, and regulatory subsystem efficiency. The level of educational activity efficiency is determined by the quality points earned after calculation.

The study was conducted in two cohorts: the 1st cohort is students of the Coach Faculty, and the 2nd cohort is students of the Sport and Management Faculty.

Two surveys were undertaken. The first survey was conducted before studying the Olympic Sports. The second one took place in the end of the educational course 'Olympic Sports'.

In this paper, such methods as the analysis of literary sources, synthesis and generalization were used to define interactive learning technologies, the use of which helps to enhance the integration of aspects of the Olympic education into the overall educational process. The application of those methods allowed to develop the content and guidelines for the use of the above-mentioned technologies. 
Statistical analysis. Statistical processing of the data was performed using the Excel 2010 spreadsheet editor (Microsoft, USA, 2010), the average was used.

Results: the expediency of Olympic education implementation in the student educational process was studied; the interactive learning technologies that will facilitate the educational process efficiency among the Physical Culture and Sports future specialists were elucidated; the efficiency of the interactive learning technologies in the Olympic education implementation was disclosed.

Conclusions: the interactive learning technologies that will felicitate the creation of a highly-qualified specialist in Physical Culture and Sports, namely: interactive cooperative learning technologies (pairwork, trio rotation, 'Carousel', 'Aquarium'); group learning technologies ('Brainstorming', "Decision Tree', 'World Café'); situational modeling technologies ('Six Hats Method', business games); argument technologies ('The PRESSING Method,' 'What? Where? When? How?' debates, etc.); and methodological materials for the students of higher educational institutions of Ukraine were produced, based upon this technology data. The use of interactive learning technologies when integrating Olympic education permits to increase the educational process efficiency and helps to improve student motivation to acquire knowledge.

\section{Introduction}

Shift of priorities and social values in today's society leads to the need for constant improvement of educational process in higher education institutions.

The experts note (Bystrova Yu.V., 2015; Gladush V.A. \& Lysenko G.I., 2014; Naul R., Binder D., Ivanenko G., 2019) that the outdated practices prevail in today's practical activity of higher educational specialized institutions, the ideas of democratization are not sufficiently implemented. The main problems in the development of higher education institutions are student low motivation to acquire knowledge and drop in attendance. This situation necessitates rethinking of the principles, functions and technologies of managing specialist training in Physical Culture and Sports and, thereupon, develops new approaches to the organization of the pedagogical process in a higher education institution.

The analysis of special scientific and methodological literature indicates that today the ways of integration of the Olympic education into the school educational process have been extensively revealed (Armor K, Dagkas S., 2012), the educational potential of the Olympic movement has been elucidated (Bulatov M. \& Platonov V., 2018), the importance of integrating Olympic education into the specialist training in Physical Culture and Sports (Radchenko LO, 2016), the activity peculiarities of the Olympic Studies Centers operating as part of the specialized higher education institutions of Ukraine (Zagitova \& Radchenko, 2019) have been disclosed, whereas the problem of improving the educational process by integrating Olympic education into the educational process of higher education institutions remains a pressing scientific matter.

Today's educational requirements include the training of highly qualified specialists who are able to integrate the theoretical knowledge and practical skills acquired at a higher educational institution into an integral system effectively used in their professional activities. In order to successfully realize personal educational potential of future specialists in Physical Culture and Sports, the development conditions of the qualities such as criticism and nonstandard thinking, the ability to produce new ideas and work in a team, etc., must be created. Such tasks are facilitated by the use of interactive learning technologies in the educational process. 
The working hypothesis is that the use of interactive learning technologies in the study of Olympic education related issues will improve the efficiency of student educational process in higher education institutions preparing future specialists in Physical Culture and Sports.

Aim of the Study: to provide the rationale for the use of interactive learning technologies while implementing the Olympic education into the student educational process.

\section{Material and methods.}

Research participants: 12 experts - members of the Olympic Academy of Ukraine, having more than 15 years of pedagogic experience at higher educational institutions, holding managerial positions at sphere-specific educational establishments.

69 students from 8 study groups of the $4^{\text {th }}$ year at the National University of Ukraine on Physical Education and Sport, who major in 0.17 'Physical Education and Sport'.

Organization of research.

The first step was to determine experts' opinion on the necessity to introduce Olympic education in the student training process.

The next step of the study was to determine the educational process efficiency according to I.S. Todorova (Todorova I.S\& Pavlenko V.I. 2011). This method employs that the respondents need to answer 20 questions that allow to determine the educational activity efficiency ratio, namely: total educational activity efficiency, motivational subsystem efficiency, operational subsystem efficiency, information subsystem efficiency, and regulatory subsystem efficiency. The level of educational activity efficiency is determined by the quality points earned after calculation.

The study was conducted in two cohorts: the 1st cohort is students of the Coach Faculty, and the 2nd cohort is students of the Sport and Management Faculty.

Two surveys were undertaken. The first survey was conducted before studying the Olympic Sports. The second one took place in the end of the educational course 'Olympic Sports'.

In this paper, such methods as the analysis of literary sources, synthesis and generalization were used to define interactive learning technologies, the use of which helps to enhance the integration of aspects of the Olympic education into the overall educational process. The application of those methods allowed to develop the content and guidelines for the use of the above-mentioned technologies.

Statistical analysis. Statistical processing of the data was performed using the Excel 2010 spreadsheet editor (Microsoft, USA, 2010), the average was used.

Results: the expediency of Olympic education implementation in the student educational process was studied; the interactive learning technologies that will facilitate the educational process efficiency among the Physical Culture and Sports future specialists were elucidated; the efficiency of the interactive learning technologies in the Olympic education implementation was disclosed.

The first step was to determine experts' opinion on the necessity to introduce Olympic education in the student training process. The results of the survey conducted allowed determining that $100 \%$ of the respondents consider it necessary to introduce Olympic education in the student training process in Ukraine. Thus, the data confirm the relevance of this study and the importance of integrating the Olympic education-related issues into the training of future specialist in Physical Culture and Sports.

Moreover, $100 \%$ of the experts believe that the introduction of Olympic education in the student educational process of higher educational institutions of Ukraine will facilitate a harmonious development of personality.

The study has allowed to establish that $75 \%$ of the experts believe it is effective to integrate Olympic education into the student educational process at the higher educational 
institution they work at. It should be noted that $25 \%$ of the respondents could not answer this question. In our opinion, this is caused by some problems regarding the introduction of Olympic education in the student training process at the higher educational institution of Ukraine

The next step of the study was to determine the educational process efficiency according to I.S. Todorova. This method employs that the respondents need to answer 20 questions that allow to determine the educational activity efficiency ratio, namely: total educational activity efficiency, motivational subsystem efficiency, operational subsystem efficiency, information subsystem efficiency, and regulatory subsystem efficiency. The level of educational activity efficiency is determined by the quality points earned after calculation.

The study was conducted in two cohorts: the $1^{\text {st }}$ cohort is students of the Coach Faculty, and the $2^{\text {nd }}$ cohort is students of the Sport and Management Faculty (Table 1). The first survey was conducted before studying the Olympic Sports.

Table 1

Estimation of the educational activity efficiency level of the third-year-students of the National University of Ukraine on Physical Education and Sport

(before the experiment)

\begin{tabular}{|c|c|c|c|c|c|c|c|c|c|c|c|}
\hline \multirow[t]{3}{*}{ No. } & \multirow[t]{3}{*}{ Efficiency ratio } & \multicolumn{10}{|c|}{ Efficiency level } \\
\hline & & \multicolumn{2}{|c|}{ very high } & \multicolumn{2}{|c|}{ high } & \multicolumn{2}{|c|}{ medium } & \multicolumn{2}{|c|}{ low } & \multicolumn{2}{|c|}{ very low } \\
\hline & & $\mathrm{A}^{*}$ & $\mathrm{~B}^{*}$ & $\mathrm{~A}^{*}$ & $\mathrm{~B}^{*}$ & $\mathrm{~A}^{*}$ & $\mathrm{~B}^{*}$ & $\mathrm{~A}^{*}$ & $\mathrm{~B}^{*}$ & $\mathrm{~A}^{*}$ & $\mathrm{~B}^{*}$ \\
\hline 1 & $\begin{array}{l}\text { E (total) is the total } \\
\text { efficiency ratio }\end{array}$ & $9 \%$ & $9 \%$ & $71 \%$ & $71 \%$ & $17 \%$ & $20 \%$ & $3 \%$ & $0 \%$ & $0 \%$ & $0 \%$ \\
\hline 2 & $\begin{array}{l}\mathrm{E}(\mathrm{m}) \text { is the motivational } \\
\text { subsystem efficiency ratio }\end{array}$ & $21 \%$ & $20 \%$ & $59 \%$ & $54 \%$ & $14 \%$ & $17 \%$ & $3 \%$ & $9 \%$ & $3 \%$ & $0 \%$ \\
\hline 3 & $\begin{array}{l}\mathrm{E}(\mathrm{o}) \text { is the operational } \\
\text { subsystem efficiency ratio }\end{array}$ & $21 \%$ & $17 \%$ & $64 \%$ & $65 \%$ & $12 \%$ & $9 \%$ & $3 \%$ & $9 \%$ & $0 \%$ & $0 \%$ \\
\hline 4 & $\begin{array}{l}\mathrm{E}(\mathrm{t}) \text { is the information } \\
\text { subsystem } \\
\text { ration }\end{array}$ & $24 \%$ & $9 \%$ & $50 \%$ & $69 \%$ & $26 \%$ & $22 \%$ & $0 \%$ & $0 \%$ & $0 \%$ & $0 \%$ \\
\hline 5 & $\begin{array}{l}\mathrm{E}(\mathrm{r}) \text { is the regulatory } \\
\text { subsystem efficiency ratio }\end{array}$ & $15 \%$ & $20 \%$ & $35 \%$ & $63 \%$ & $41 \%$ & $11 \%$ & $9 \%$ & $0 \%$ & $0 \%$ & $0 \%$ \\
\hline
\end{tabular}

$A^{*}$ - students of the Coach Faculty;

$B^{*}$ - students of the Sport and Management Faculty

The comparison of the survey results at the Coach Faculty and the Sports and Management Faculty, according to the Student's $t$ test $(t=-0.17)$, allows to predetermine the uniformity of the selection.

The study results show that $9 \%$ of the students of the Coach Faculty and $9 \%$ of the students of the Sports and Management Faculty observed a very high total efficiency level of the educational process, $71 \%$ and $71 \%$, respectively, observed a high level, $17 \%$ and $20 \%$ average level, 3\% of the students of the Coach Faculty observed a low level of total educational process efficiency level, which confirms the need to improve the educational process through the interactive learning technologies, namely, the methodological technologies developed by us.

The next step of the study was to determine the motivational subsystem efficiency, which reflects the level of student educational activity and orientation. Thus, $21 \%$ of the 
students of the Coach Faculty and $20 \%$ of the students of the Sports and Management Faculty noted a very high level of the motivational subsystem development, 59\% and 54\%, respectively, of the respondents observed a high level, $14 \%$ and $17 \%$ - a medium level, $3 \%$ and $9 \%$ - a low level. It should be noted that 3\% of the students of the Coach Faculty identified a very low level of motivation for educational activity, which indicates that students are not interested in the educational process or are inactive during class time.

The survey revealed the operational subsystem efficiency level, which determines students 'ability to carry out educational activities, quality of educational activity and actions, students' understanding of what to do and how to act at lectures, seminars, practical classes.

Thus, $21 \%$ of the students of the Coach Faculty observed a very high operational subsystem efficiency level, 64\% of the respondents observed a high level, 12\% - medium, and 3\% - a low level. 17\% of the students of the Faculty of Sports and Management Faculty observed a very high operational subsystem efficiency level, $65 \%$ of the respondents observed a high level, $9 \%$ - a medium level, and 9\% - a low level. Generally speaking, it is necessary to mark the necessity to increase the subsystem level efficiency by implementing new forms and technologies of the educational process.

The next step of the study was to determine the information subsystem efficiency level that reflects the quantitative and qualitative characteristics of the information provision of educational activity, its professional orientation, systematization and accessibility for assimilation, the relationship of information provided with future practical activity. A very high information subsystem efficiency level was observed by $24 \%$ of the respondents of the Coach Faculty and 9\% of the Sports and Management Faculty, 50\% of the students of the first cohort and $69 \%$ of the students of the second cohort observed a high level, $26 \%$ and $22 \%$, respectively, observed a medium efficiency level. It should be noted that none of the respondents identified the low and very low information subsystem efficiency level.

The survey conducted permitted to evaluate the regulatory subsystem efficiency level that characterizes the student functional state, namely the level of tension, mood, fatigue during class time; provision and nature of external control of the teacher (educational department, dean's office); the self-control development level; the student-teacher feedback efficiency. Thus, $15 \%$ of the students of the Coach Faculty observed a very high regulatory subsystem efficiency level, 35\% of respondents identified a high level; $41 \%$ - a medium level, and $9 \%$ - a low level. It is determined that $20 \%$ of the students of the Sports and Management Faculty have a very high regulatory subsystem efficiency level, 63\% observed a high efficiency level, 11\% - medium, and 6\% - low. The survey showed the need to improve the student-teacher feedback efficiency and to create student motivation to perform independent work.

At the present time, the main task of a higher educational institution is to train specialists who are able to respond non-standard, in a flexible and timely manner to the changes taking place in the world. Thus, student educational process should be approached not only with uniform and traditional learning technologies, but also using innovative learning approaches (Bystrova Yu, 2015).

The innovative learning technologies include interactive learning. It is aimed at active and deep mastering of the material studied as well as developing the ability to solve complex problems. The interactive learning technologies involve continuous interaction, dialogue, conversation between a teacher and a student, and the dominating role should be taken by the students, while the teacher should set the pace in the class.

In order to determine the peculiarities of the use of interactive learning technologies when implementing Olympic education in the student educational process, we have been allocated interactive learning technologies that will facilitate the training of a highly qualified specialist in Physical Culture and Sports: 
'Aquarium');

- interactive cooperative learning technologies (pairwork, trio rotation, 'Carousel',

- group learning technologies ('Brainstorming,' "Decision Tree,' 'World Café');

- situational modeling technologies ('Six Hats Method,' business games);

- argument technologies ('PRESSING method,' 'What? Where? When? How?'

debates, etc.)

The researches undertaken allowed to create methodological materials for the Olympic Sports Course, which is taught to the third-year-students studying in Physical Culture and Sports at the National University of Ukraine on Physical Education and Sports of Ukraine.

In general, some interactive learning technologies were selected, business games were offered, and the films for individual viewing were recommended which covered 15 topics of the course: Subject, Content and Basic Concepts of the Olympic Sport Course, Olympic Games of Ancient Greece, Renaissance of the Olympic Games, Modern Olympic Games, Olympic Movement in Ukraine, Structure of the International Olympic Movement, International Olympic Committee: History, Structure, Functions, International and National Sports Organizations, Legal Foundations of the Olympic Movement, Economic Programs of the Olympic Movement, Organization and Conduct of the Olympic Games, Program of the Olympic Games, Olympic Education: History, Structure, Functions, Olympic Sports and Politics, Actual Problems of the Modern Olympic Movement (Table 2).

Methodological material for the Olympic Sport discipline as exemplified in the topics: Subject, Content and Basic Concepts of the Olympic Sports, Ancient Greek Olympics courses

\begin{tabular}{|l|l|l|}
\hline No. & Name of topic & Methodical material \\
\hline 1. & $\begin{array}{l}\text { Subject, content } \\
\text { and basic } \\
\text { concepts of the } \\
\text { Olympic Sports } \\
\text { course }\end{array}$ & $\begin{array}{l}\text { 1. Didactic game 'Alias' for effective study of the basic discipline } \\
\text { terms. } \\
\text { 2. Creation of a thematic crossword puzzle - for effective } \\
\text { consolidation of the learned material. } \\
\text { 3. Trio rotation to discuss the social nature of the Olympic } \\
\text { movement (search for answers to the question: What values does the } \\
\text { Olympic movement pursue? What are the disadvantages of the } \\
\text { Olympic philosophy?). The use of this method will facilitate active } \\
\text { and thorough analysis of new material. }\end{array}$ \\
\hline 2. & $\begin{array}{l}\text { Ancient } \text { Greek } \\
\text { Olympics }\end{array}$ & $\begin{array}{l}\text { 1. Organization of sports competitions among students according to } \\
\text { the Ancient Olympic Games scenario in order to consolidate } \\
\text { knowledge on the subject, improve organizational and } \\
\text { communication skills, and increase motor activity. } \\
\text { 2. Knowledge control using Kahoot online service. The use of this } \\
\text { service will increase the information and communication literacy of } \\
\text { the student. } \\
\text { 3. 'Chamomile' - students are given a topic of the game with the } \\
\text { numbered questions. Then, the students take turns answering } \\
\text { questions, repeating the answer of the previous participant. At the } \\
\text { end of the game, a detailed answer is formed on the topic of the } \\
\text { lesson. This technique will help you remember new material more } \\
\text { effectively. }\end{array}$ \\
\hline
\end{tabular}

It should be noted that the methodological materials were introduced into the third-yearstudent educational process of the Coach Faculty. 
The next step of the study was to conduct a second survey according to I.S. Todorova, among the third-year-students of the National University of Ukraine on Physical Education and Sport after integrating the methodological materials, created by us (Table 3 ).

Analyzing the total educational process efficiency ratio, $17 \%$ of the respondents of the Coach Faculty observed a very high level, $83 \%$ - a high level. None of the students noted medium, low and below medium, which indicates a significant improvement in the student educational process efficiency.

Table 3

Estimation of the educational activity efficiency level of the third-year-students of the National University of Ukraine on Physical Education and Sport (after the experiment)

\begin{tabular}{|c|c|c|c|c|c|c|c|c|c|c|c|}
\hline \multirow[t]{3}{*}{ No. } & \multirow[t]{3}{*}{ Efficiency ratio } & \multicolumn{10}{|c|}{ Efficiency level } \\
\hline & & \multicolumn{2}{|c|}{ very high } & \multicolumn{2}{|c|}{ high } & \multicolumn{2}{|c|}{ medium } & \multicolumn{2}{|c|}{ low } & \multicolumn{2}{|c|}{ very low } \\
\hline & & $\mathrm{A}^{*}$ & $\mathrm{~B}^{*}$ & $\mathrm{~A}^{*}$ & B* & $\mathrm{A}^{*}$ & $\mathrm{~B}^{*}$ & $A^{*}$ & $\mathrm{~B}^{*}$ & $\mathrm{~A}^{*}$ & $\mathrm{~B}^{*}$ \\
\hline 1 & $\begin{array}{l}\text { E (total) is the total } \\
\text { efficiency ratio }\end{array}$ & $17 \%$ & $10 \%$ & $83 \%$ & $68 \%$ & $0 \%$ & $22 \%$ & $0 \%$ & $0 \%$ & $0 \%$ & $0 \%$ \\
\hline 2 & $\begin{array}{l}\mathrm{E}(\mathrm{m}) \text { is the } \\
\text { motivational subsystem } \\
\text { efficiency ratio }\end{array}$ & $25 \%$ & $17 \%$ & $58 \%$ & $52 \%$ & $17 \%$ & $21 \%$ & $0 \%$ & $10 \%$ & $0 \%$ & $0 \%$ \\
\hline 3 & $\begin{array}{l}\text { E (o) is the operational } \\
\text { subsystem efficiency } \\
\text { ratio }\end{array}$ & $17 \%$ & $17 \%$ & $83 \%$ & $60 \%$ & $0 \%$ & $13 \%$ & $0 \%$ & $10 \%$ & $0 \%$ & $0 \%$ \\
\hline 4 & $\begin{array}{l}\text { E (t) is the information } \\
\text { subsystem efficiency } \\
\text { ration }\end{array}$ & $17 \%$ & $10 \%$ & $83 \%$ & $70 \%$ & $0 \%$ & $20 \%$ & $0 \%$ & $0 \%$ & $0 \%$ & $0 \%$ \\
\hline 5 & $\begin{array}{l}\mathrm{E}(\mathrm{r}) \text { is the regulatory } \\
\text { subsystem efficiency } \\
\text { ratio }\end{array}$ & $17 \%$ & $17 \%$ & $75 \%$ & $64 \%$ & $8 \%$ & $19 \%$ & $0 \%$ & $0 \%$ & $0 \%$ & $0 \%$ \\
\hline
\end{tabular}

$\mathrm{A}^{*}$ - students of the Coach Faculty;

$\mathrm{B}^{*}$ - students of the Sport and Management Faculty

Repeating the survey undertaken allowed us to assess the motivational subsystem efficiency level. Thus, 25\% of the respondents of the Coach Faculty observed a very high level, 58\% - a high level, 17\% - a medium level. These data indicate that students have improved class activity as well as attendance. During the educational process, students were more initiative and diligent.

The survey found that $17 \%$ of the students reported a very high operational sub-system level, and $83 \%$ reported a high level. During the implementation of the methodological material developed by us, it was noted that the students of the Coach Faculty increased the speed and improved the quality of learning activity.

During the survey, the information subsystem efficiency was repeatedly determined by the respondents. Thus, $17 \%$ of the students of the Coach Faculty indicated a very high level, $83 \%$ - a high efficiency level. These data indicate that the proposed methodological material was more systematic and accessible for learning.

The study undertaken showed that the regulatory subsystem performance improved. Thus, $17 \%$ of the respondents observed a very high level, $75 \%$ - a high level and $8 \%-$ a medium level. These indicators suggest that through the use of interactive learning 
technologies, the students have reduced emotional tensions in the class time, and improved student-teacher and student-student feedback.

It should be noted that the survey results of the students of the Sports and Management Faculty have not changed significantly.

Comparison of the results of the survey of students of the Coach Faculty and the Sports and Management Faculty according to the Student's $t$ test $(t=-1.4)$, suggests that the samples upon the indicators studied are not homogeneous.

The results of the study undertaken confirm the efficiency of using interactive teaching technologies when integrating Olympic education into the student educational process, namely, the use of these technologies allows to increase students' activity and interest in the class, non-standard thinking, withdraw from stereotypes, and foster communication knowledge and skills.

\section{Discussion}

The results of the research allow to confirm claims of experts (Naul, R., Binder, D., Rychtecky, A., 2017; Lenskyj, H., 2012) that the integration of the Olympic education into the overall educational process is an effective means of improvement of the quality preparation of the sports professionals. They also note that the peculiarities of the integration of the Olympic education into the educational process of students of higher educational institutions of Ukraine lie in the fact that most institutions incorporate certain aspects of the Olympic education into the study of academic disciplines. The most common discipline into which Olympic education issues are introduced is Olympic and Professional Sports.

The attained results confirm the statements of experts on the practicability of use of interactive technologies within the framework of the educational process (Abykanova B., 2016; Radchenko M., 2014). At the same time, the initiative to implement aspects related to the Olympic education along with the introduction of interactive technologies into the educational process is a novelty.

In general, having analysed the results of the research, we established that the application of the proposed approach to the integration of the Olympic education into the educational process of the NUUPES students helped to improve the overall efficiency of the educational process by $10 \%$. Considering each efficiency factor of educational activity separately, we determined that the indicators of the level of efficiency of the motivational subsystem and the operating subsystem were improved by $15 \%$; whereas, the indicators of the efficiency of the information subsystem increased by $20 \%$. The level of efficiency of the regulatory subsystem among students demonstrated the most substantial increase - by $25 \%$. These indicators confirm the practicability of use of interactive learning technologies for the implementation of the Olympic education into the overall educational process of student youth.

\section{Conclusions}

The interactive learning technologies that will felicitate the creation of a highlyqualified specialist in Physical Culture and Sports, namely: interactive cooperative learning technologies (pairwork, trio rotation, 'Carousel', 'Aquarium'); group learning technologies ('Brainstorming', "Decision Tree', 'World Café'); situational modeling technologies ('Six Hats Method', business games); argument technologies ('The PRESSING Method,' 'What? Where? When? How?' debates, etc.); and methodological materials for the students of higher educational institutions of Ukraine were produced, based upon this technology data. The use of interactive learning technologies when integrating Olympic education permits to increase the educational process efficiency and helps to improve student motivation to acquire knowledge. 
1. In many countries of the world, including Ukraine, educationalists search for new focus areas to enhance the education of moral and ethical qualities and formation of spiritual values through the introduction of the Olympic education among students of higher education institutions. The analysis of special scientific and methodical literature allowed to establish that nowadays the social significance of the introduction of the Olympic education has been deeply substantiated; its historical aspects have been studied, and the peculiarities of the Olympic education in the country have been revealed; the ways of integration of the Olympic education into the education of school and student youth have been outlined; the educational potential of the Olympic movement has been highlighted. However, the problem of integration of the Olympic education into the educational process of sphere-specific higher educational institutions remains a topical scientific issue.

2. The peculiarities of integration of the Olympic education into the educational process of students of higher educational institutions are such that the majority of higher educational institutions of Ukraine incorporate certain aspects of the Olympic education into the study of academic disciplines. The most common discipline into which Olympic education issues are introduced is Olympic and Professional Sports.

3. The research has allowed its authors to identify integrative technologies for the implementation of the Olympic education into the overall educational process, to develop teaching materials, to test and confirm their effectiveness.

\section{Conflict of interest}

The authors state that there are no conflicts of interest.

\section{References:}

Abykanova, B. (2016). The Use of Interactive Learning Technology in Institutions of Higher Learning. International journal of environmental \&science education. 18:12528-39

Amemado, D. (2014). Integrating technologies in higher education: The issue of recommended educational features still making headline news. Open Learning: The Journal of Open, Distance and e-Learning.29(1):15-30. https://doi.org/10.1080/02680513.2014.908700

Armour K, Dagkas S. (2012). Olympism and education: a critical review. Educational Review.64(3):261-4. https://doi.org/10.1080/00131911.2012.704742

Binder, D. (2017) Canada: Olympic education programmes as legacies of Olympic Games. In: Naul R, Binder D, Rychtecky A, Culpan I, editors. Olympic education: an international review. New York: Taylor \& Francis. 104-18. https://doi.org/10.1080/00131911.2012.676539

Bronikowski., M, Bronikowska, M., Glapa, A. (2017). Poland: Olympic education as patterns of sport instittutions. In: Naul R, Binder D, Rychtecky A, Culpan I, editors. Olympic education: an international review. New York: Taylor \& Francis:222-37.

Bistrova, U. (2015) Innovative Methods of learning in the Higher School of Ukraine. Law and Innovation Society. 1(4):27-33.

Bulatova M., Georgiadis K. (2016). International Olympic Academy in the system of education and upbringing. Science in Olympic sports.3:4-13.

Bulatova, M., Platonov, V. (2018). Olympism and Olympic education: history, modernity, future. Science in Olympic sports. 4:4-27. https://doi.org/10.32652/olympic2018.4_1

Chilwant K.S. (2012).Comparsion of two teaching methods, structured interactive lectures and conventional lectures. Biomedical Research. 23(3):363-66.

Devine, C. (2013). London 2012 Olympic legacy: a big sporting society? International Journal of Sport Policy and Politics. 5(2):257-9. https://doi.org/10.1080/19406940.2012.656674 
Georgiadis, K. (2005). The Olympic education program of the Organizing Committee of the Olympic Games Athens 2004 and the Greek Ministry of Education. In: IOA, editor. 45th Session for Young Participants; Olympia. 120-45.

Gladush, V., Lysenko, G. (2014). Higher education pedagogy: theory, practice, history. Dnypro, $416 \mathrm{p}$.

Haijun Zhang, Guo Xiatao, Zhang Shangyan. (2017).Research on the Reason of Olympic Internationalization Succes from the Cross-culture Perspective. Open Access Journal of Science. 1(6): 1-6. https://doi.org/10.15406/oajs.2017.01.00033

Horodynskyy S.I., Ibragimova L.S. (2017). Features introduction of Olympic education in the educational process in Ukraine. Young Scientist. 3.1(43.1): 99-2.

Ivanenko H. (2017). Problems of realization of the Olympic education Ukrainian universities and ways of overcoming them (view of students). Theory and methods of Physical Education and Sports.4:23-6.

Ivanenko, H. (2019). Olympic education in the system of preparation of specialists in the specialty "Physical Culture and Sports" in Ukraine. Prydniprovsky Sports Newsletter. 1:25-32. DOI: 10.32540/2071-1476-2019-1-025

Kozatek, A., Uzhvenko, K., Duchnova, L., Radchenko, L, Krol, I., Ulan, A., D’omina, A., Borysova, O., Denysova, L., Shi Shengying (2020). Sustainable development and the olympic movement. Journal of Physical Education and Sport (JPES). 20 (1): 403-7. DOI:10.7752/jpes.2020.s1057

Lenskyj, H. (2012). Olympic education and Olympism: Still colonizing children's minds. Educational Review. 64(3):265-74. https://doi.org/10.1080/00131911.2012.667389

Lyras A. (2014). Olympic education in practice: educational components of a sport for peacebuilding intervention. In: Chatziefstathiou D, Muller N, editors. Olympism, Olympic education and learning legacies. Newcastle upon Tyne: Cambridge scholars Publishing: 245-58.

Minnaert, L. (2012). An Olympic legacy for all? The non-infrastructural outcomes of the Olympic Games for socially excluded groups (Atlanta 1996-Beijing 2008). Tourism Management. 33(4):361-70. https://doi.org/10.1016/j.tourman.2011.04.005

Muller, N., editor. (2000). Pier de Coubertin. Olimpism. Selected Writings. Lausanne: IOC: 281-283.

Naul, R., Binder, D., Rychtecky, A., \& Culpon, I. (2017). Olympic Education: an internatsonal review. Discription: Abingdon, Oxon; New York, NY: Routbedge is an imprint of the Taylor \& Francis Group, an Informa Busines, $361 \mathrm{p}$.

Radchenko M.A. (2014). Interactive learning technologies in the professional formation future specialist. Pedahohika formuvannya tvorchoyi osobystosti u vyshchiy $i$ zahal'noosvitniy shkolakh.34:299-06.

Radchenko, L. (2016) Stages of realization of Olympic education in activity of higher profile educational institutions. Scientific journal of M.P. Dragomanov National Pedagogical University. 6 (76): 95-8.

Roux Charl J., Janse van Rensburg Natasha. (2017). An outdoor adventure programme infused with Olympic values in teaching Olympism to university students. South African Journal for Research in Sport, Physical Education and Recreation.1-2: 63-77.

Raman Santhiram. (2016). Emerging Trends in Higher Education Pedagogy. WOU Press. $2: 82$.

Todt NS. (2014). Worldwide practices combining Olympic values and sport: encouraging transferable life skills to Disadvantaged Brazilian Communities. In: Chatziefstathiou D, Muller N, editors. Olympism, Olympic education and learning legacies. Newcastle upon Tyne: Cambridge scholars Publishing. 194-206. 
Todorova I., Pavlenko V. Psykholohiia i pedahohika: navchalnyi posibnyk. K: Tsentr uchbovoi literatury, 2011.180-185.

Zagitova, M., Radchenko, L. (2019). Organizational bases of activity of the regional centers of Olympic researches and education in Ukraine. Science in Olympic sports. 1:49. doi:10.32652/olympic2019.1_1 